\title{
Neurocognitive dysfunctions and functional state of patients after internal carotid endarterectomy
}

\author{
Dorota Kozak-Putowska', Joanna Iłżecka², Tomasz Zubilewicz' \\ 'Chair and Department of Vascular Surgery and Angiology, Medical University of Lublin, Poland \\ ${ }^{2}$ Independent Neurological Rehabilitation Unit, Medical University of Lublin, Poland
}

\begin{abstract}
Introduction. Carotid endarterectomy (CEA) is a method of treatment of carotid stenosis, which significantly reduces the risk of ischemic stroke. This procedure may affect the patient's neurocognitive functioning. The aim of the study was to evaluate the occurrence of neurocognitive disorders and to determine the functional status of the patients undergoing CEA.

Material and methods. The study group consisted of 102 people who underwent CEA. Studies were performed preoperatively and repeated on the fourth postoperative day. The following scales were used: the Mini-Mental State Examination (MMSE), Activities of Daily Living Scale (ADL), Instrumental Activities of Daily Living (IADL) and the Hamilton Depression Rating Scale (HAM-D).

Results. The average number of points obtained by patients in the MMSE, both before and after surgery is 26 points to 30 that may be obtained, which shows a subtle cognitive impairment. Almost every patient showed fitness both in terms of basic (ADL), as well as complex (IADL) activities before and after surgery.

Conclusions. Low or average level of cognitive performance is observed in most subjects, both before and after CEA. There are many different factors that can affect the cognitive functions. The functional status of patients stood without significant changes.
\end{abstract}

Key words: endarterectomy, internal carotid artery, cognitive impairment, functional state

Acta Angiol 2018; 24, 3: 86-92

\section{Introduction}

Carotid endarterectomy (CEA) is a method of treatment of carotid stenosis, which significantly reduces the risk of ischemic stroke [1-7]. The efficacy and safety of CEA in symptomatic patients were randomized confirmed two key studies: NASCET (North American Symptomatic Carotid Endarterectomy Trial) and ECST (European Carotid Surgery Trial) [2, 3]. Treatment of asymptomatic patients was based on the studies: ACAS (Asymptomatic Carotid Atherosclerosis Study) and ACST (Asymptomatic Carotid Surgery Trial) [4, 5]. Selection procedure between endarterectomy and carotid artery angioplasty depend on the general patient's con- dition, concomitant diseases, anatomical characteristics of vessels and morphology, size, structure and surface characteristics of atherosclerotic plaque [8].

There are publications which show that the internal carotid artery stenosis, as well as the operation of CEA, worsens cognitive functioning, while others show no improvement or any change in this area. They do not set clear guidelines for test methods or specific neuropsychological test battery for the assessment of cognitive functions, which should be used in patients with stenosis of the internal carotid artery after surgery or CEA [7, 9-II].

Neurocognitive deficits impair the functional status and the impact on quality of life [12]. Evaluation of cog- 
nitive and functional state allows to identify groups of patients susceptible to changes in this area and allows for appropriate therapeutic management.

The aim of the study was to:

I. Evaluate the occurrence of neurocognitive disorders

2. Determine the functional status of the patients undergoing CEA.

The resulting posed to the root problem was: are neurocognitive disorders occur before and after the short-term treatment of carotid endarterectomy and do they affect the functional status of the patient?

\section{Material and methods}

The study group included 102 patients who were hospitalized at the Chair and Department of Vascular Surgery and Angiology, Medical University in Lublin and underwent CEA. The study was conducted in the period from September 2014 to August 2016.

There were treated 40 women (39.22\%) and 62 men $(60.78 \%)$. Age ranged from 65 to 80 years (mean age 67.5 years). Patients were divided into two groups. The first group consisted of symptomatic patients $29.41 \%$ (paresis, paralysis, speech disorders, memory disorders, vision disorders), the second group consisted of asymptomatic patients (70.59\%).

Diseases that could influence cognitive function in the study group are hypertension (53.92\%) and other diseases $(37.25 \%)$, and a history of stroke $(30.39 \%)$, diabetes (21.57\%), less myocardial infarction (14.71\%), and other cardiac disease $(20.59 \%)$. There were no other neurological diseases and depression. Smoking declared $72.55 \%$ of respondents. Studied patients in $100 \%$ do not abuse alcohol or other drugs and there were no head injuries among them.

Patients were qualified for surgery by a vascular surgeon based on the recommendations of the European Society for Vascular Surgery. There was conducted detailed medical history, assessment of patient's general condition, and the evaluation of the overall anatomical features of vessels, the degree of stenosis and the opposing status of the internal carotid artery by Doppler ultrasound (US). In the preoperative period was not performed CT examination of the brain.

Before surgery, each patient was also consulted by a neurologist and anesthesiologist. The patient was prepared for surgery by premedicated with oral midazolam or Hydroxyzinum, in patients with chronic hypertension or heart diseases is not interrupted the supply of drugs taken on a permanent basis.

The surgery was performed by an experienced vascular surgeon, under local anaesthesia, with shunting used selectively. Classical method without a patch was used the most often. A shunt was selectively used if the patient lost contact during test clamping of the internal carotid artery (clamping tolerance). None of the respondents had intraoperative or postoperative neurological events, so there was no need for the control of CT in the postoperative period.

Cognitive function was assessed using the Mini Mental State Examination (MMSE), which gives the opportunity to evaluate orientation in place and time, verbal memory, attention, counting, recalling, language functions, command execution, writing and visual-spatial analysis. The purpose of the scale is the initial assessment of the patient's condition and determine who requires more detailed studies neuropsychological tests. Functional status was assessed used Activities of Daily Living scale (ADL), Instrumental Activities of Daily Living Scale (IADL) and the Hamilton Depression Rating Scale (HAM-D). The above-mentioned tests were performed preoperatively (on the day preceding surgical procedure) and subsequently repeated on the fourth postoperative day. None of the patients had procedure-related complications.

To conduct the study there was given a permission by the local Bioethical Commission (No. KE-0254/269/2014).

Statistical analysis was performed using STATISTICA software for Windows 12.0 (StatSoft, Poland). The following tests were used: the Shapiro-Wilk test, the Mann-Whitney $U$ test, the Kruskal-Wallis test, the Spearman's rank correlations, chi-squared test, Wilcoxon matched-pairs test and logistic regression. The statistical significance level was set at a P-value of $<0.05$.

\section{Results}

The total score achieved by patients in the MMSE scale before treatment is presented in Figure I. The largest number of respondents - 52 (50,98\%) achieved 27-30 points and indicate proper cognitive functioning. Other people achieved following score: $24-26$ points - 33 people $(32.35 \%)$, 19-23 points - II people $(10.78 \%)$ and $\mathrm{II}-18$ points -6 people $(5.88 \%)$. The result in the range of $2 \mathrm{I}-26$ points suggests a slight cognitive impairment. The result in the range of I I-20 points, according to the interpretation of the test, moderate cognitive impairment. There was excluded deep cognitive impairment because none of the patients achieved $0-10$ points. It must be emphasized that the MMSE scale as a screening tool is not the test for a certain diagnosis. It only suggests the possibility of cognitive impairment and the need for further research. The analysis of the particular components of the MMSE test revealed that most of the patients obtained almost maximal score, with the exception of attention and calculation. The results were similar after the procedure. 


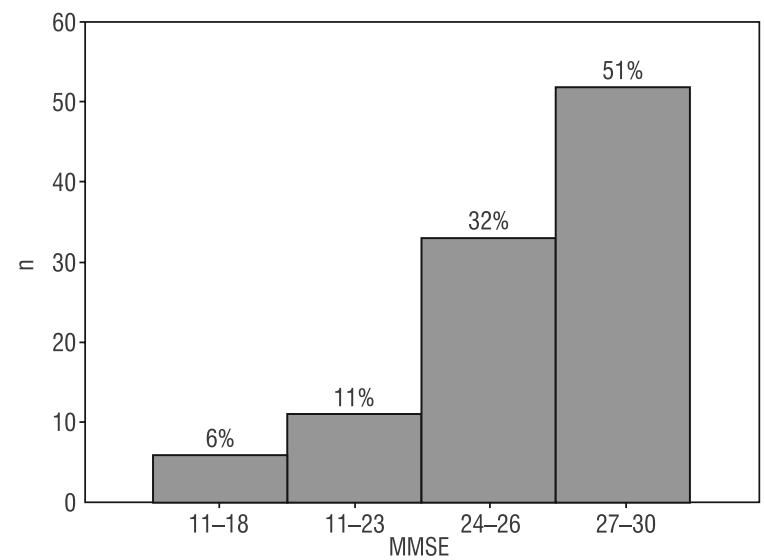

Figure I. Scores obtained by the subjects in the MMSE test before surgery

The analysis demonstrated that the level of cognitive activity did not change after the CEA, the average number obtained from patients in the MMSE scale before treatment was 26.02 and 26.21 after the treatment (Table I). The percentage of people whose result indicated a cognitive deficit amounted to $49.01 \%$ before surgery and $40.18 \%$ after the procedure.

There were no statistically significant differences in the assessment of the level of cognitive activity (MMSE) before and after surgery in symptomatic and asymptomatic patients. Taking into consideration the pre- and postoperative evaluation the improvement was observed postoperatively in $45.10 \%(n=46)$ of patients, the deterioration in $25.49 \%(n=26)$ of patients and there was no changes in $29.41 \%(n=30)$ of them (Fig. 2).

The CEA may result in the slightly more deterioration of neurocognitive function in asymptomatic patients (26.39\%) than symptomatic $(23.33 \%)$ but there is no statistical significance.

In this study also verified which demographic variables (gender, age, education, place of residence, marital status) differentiate the results obtained by MMSE scale. Statistical significance demonstrated only two variables: age and education. Worse level of cognitive performance was observed in elderly patients. Low level of cognitive performance was more often

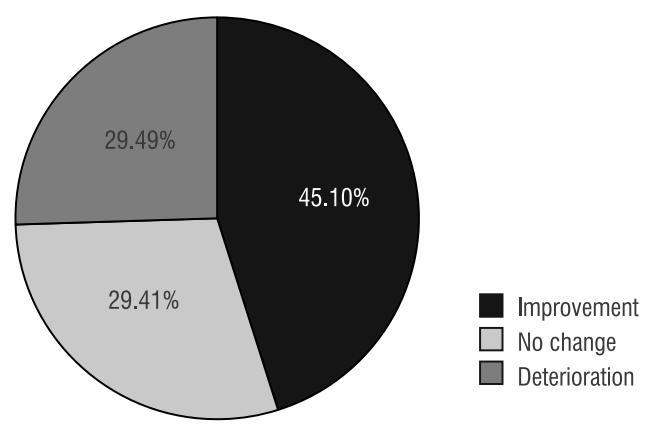

Figure 2. Distribution of respondents with regard to the assessment of changes in the level of cognitive activity after surgery

observed in patients with primary education (45.45\%) than in patients with secondary ( $17.65 \%)$ and university education (9.10\%) (Table 2).

In assessing the level of independence in performing basic (ADL) and complex (IADL) activities of daily living before and after surgery, there was no statistically significant difference between the two groups. Almost all subjects were self-dependent before (97.06\%) and $(96.08 \%)$ after the procedure. However, results indicate that higher level of complex daily activities (IADL) is observed in patients with average or high level of cognitive performance preoperatively than in patients with low level of cognitive performance and it was statistically significant $(p=0.02)$. This indicates a relationship between the level of neurocognitive function and the level of the patient's functional capacity in terms of IADL.

In order to determine the potential impact of the mental state on the level of cognitive and functional status, there was performed the evaluation of the presence or not of depressive disorders. More intensive depressive disorders were observed postoperatively and it was statistically significant $(p<0.05)$ (Table 3 ). Besides, significantly more mood disorders were observed in patients with neurological symptoms both before and after surgery.

The model of logistic regression was used to check the impact of few factors on the dependent variable and results show that old stroke is the factor that predicts

Table I. Assessment of the level of cognitive activity (MMSE) before and after surgery

\begin{tabular}{|l|c|c|c|c|c|}
\hline Testing time & Moderate & SD & Lower quartile & 24,00 & 27.00 \\
\hline Before surgery & 26,02 & 3.30 & 25.00 & 27.00 \\
\hline After treatment & 26.21 & 3.46 & 29.00 & 25.00 \\
\hline Statistical analysis: $Z=1.28 ; p=0.20$ & & & \\
\hline
\end{tabular}


Table 2. The level of cognitive activity and education

\begin{tabular}{|c|c|c|c|c|}
\hline \multirow[t]{4}{*}{ Education } & \multicolumn{3}{|c|}{ Level of cognitive performance } & \multirow[t]{2}{*}{ Generally } \\
\hline & Low & Moderate & High & \\
\hline & $\mathbf{n}$ & $\mathbf{n}$ & $\mathbf{n}$ & $\mathbf{n}$ \\
\hline & $\%$ & $\%$ & $\%$ & $\%$ \\
\hline \multirow[t]{2}{*}{ University education } & I & 5 & 5 & 11 \\
\hline & $9.10 \%$ & $45.45 \%$ & $45.45 \%$ & $100.00 \%$ \\
\hline \multirow[t]{2}{*}{ Secondary education } & 6 & 17 & 11 & 34 \\
\hline & $17.65 \%$ & $50.00 \%$ & $32.35 \%$ & $100.00 \%$ \\
\hline \multirow[t]{2}{*}{ Vocational education } & 10 & 19 & 6 & 35 \\
\hline & $28.57 \%$ & $54.29 \%$ & $17.14 \%$ & $100.00 \%$ \\
\hline \multirow[t]{2}{*}{ Primary education } & 10 & 11 & $\mathrm{I}$ & 22 \\
\hline & $45.45 \%$ & $50.00 \%$ & $4.55 \%$ & $100.00 \%$ \\
\hline \multirow[t]{2}{*}{ Altogether } & 27 & 52 & 23 & 102 \\
\hline & $26.47 \%$ & $50.98 \%$ & $22.55 \%$ & $100.00 \%$ \\
\hline \multicolumn{5}{|c|}{ Statistical analysis: $\mathrm{Chi}^{2}=13.08 ; \mathrm{p}=0.04^{*}$} \\
\hline
\end{tabular}

Table 3. Assessment of the level of depression (HAM-D) before and after surgery

\begin{tabular}{|l|c|c|c|c|c|}
\hline \multicolumn{2}{|c}{ Moderate } & SD & Lower quartile & Median & $\begin{array}{c}\text { The upper quar- } \\
\text { tile }\end{array}$ \\
\hline Before surgery & 6.76 & 4.23 & 4.00 & 7.00 & 9.0 \\
\hline After treatment & 7.40 & 4.88 & 4.00 & 7.00 & 10.0 \\
\hline Statistical analysis: $Z=4.77 ; p=0.000002 *$
\end{tabular}

patients' neurocognitive, functional and emotional before and after CEA. A similar effect has atherosclerotic disease.

\section{Discussion}

Literature proved that postoperative subtle neurocognitive dysfunctions resulting from CEA may appear in approximately $25 \%$ of patients [13-15]. This statement is confirmed in the own research. Patients obtained 26 points out of 30 possible to achieve in MMSE scale, both before and after surgery what indicate a subtle cognitive impairment without dementia and suggest the need for further research using more professional neuropsychological tests. Studies that performed research, using like at work the MMSE test, find a variety of results.

Takaiwa et al. [16] demonstrated that neurocognitive function deteriorated in approx. $30 \%$ cases week after CEA, but has improved after three months and was maintained for about a year after surgery. Other authors observed improvement in patients 6 months after CEA in terms of memory and attention [17]. It was found no differences in the assessment of cogni- tive functions in patients before and after surgery [18]. According to Soinne et al. [19] patients obtained lower score after CEA, while Capoccia et al. [20] proved an increase in the number of points in the re-examination, but the difference was statistically not significant, and the evaluation was performed in a long period after CEA.

The limitation of the comparative analysis of own results with the results of other authors is the variety of tests chosen for each research. MMSE test study gives information about the patients' global neurocognitive performance before and in the early postoperative period after endarterectomy. But detailed neuropsychological assessment is only possible using a specific battery of tests that examine specific areas of cognitive functioning.

A large number of risk factors (hypertension, diabetes, myocardial infarction, other heart disease, stroke, smoking) and sociodemographic factors (gender, age, occupation, place of residence, marital status, education) increase the risk of postoperative complications and predispose to cognitive impairment [21, 22]. Taking this into account and made an additional analysis that demonstrated the relationship between age and edu- 
cation and cognitive status. Advanced age correlates with obtaining a lower score in tests used to evaluate neurocognitive disorders [23]. In the literature, as in work also demonstrated that the low educational level decreases the efficiency of cognitive function [24, 25].

Multifactorial analysis showed that vascular risk factors such as hypertension, diabetes, stroke, heart attack and other heart disease predict patients' cognitive performance before and after surgery. In more than half of stroke patients are reflected in large-scale cognitive dysfunctions [26], which again shows how many different factors may cause neurocognitive changes in patients with internal carotid artery stenosis and after CEA.

The test results showed no statistically significant differences in the assessment of the functional fitness of both primary (ADL) and complex (IADL) activities of daily living before and after surgery, but there was observed the relationship between the level of neurocognitive performance and level of complex daily activities IADL. The higher level of neurocognitive performance, the greater efficiency in complex activities of daily living. Analyzing these results, it can be assumed that people with low level of neurocognitive activity are more likely to become not self-reliant and require care than a group of people with high level of neurocognitive activity. The literature provides varied data. Research performed by McGuire et al. [27] concluded that cognitive performance does not prognosticate ADL activities, but affect IADL activities. According to other authors [28] patients were less self-dependent in terms of basic daily activities six months after carotid endarterectomy, but their quality of life improved significantly. The study of Landgraff et al. [29] showed no evidence of deterioration in complex daily activities examined by IADL scale.

Depressive disorders significantly faster affect cognitive deterioration [30] Therefore, for a full evaluation of the functional status, there was also made an assessment of patients' emotional state using Hamilton Depression Rating Scale. Analysis of the results revealed more intensified depressive disorders after treatment and increased incidence of these disorders in symptomatic patients. There is known evidence of the relationship between depression and stroke [3I], what explains the fact of worse mental functioning symptomatic patients. Depression correlates with the deterioration of certain areas of cognitive functioning. In addition, the co-occurrence of mood disorders in patients with carotid atherosclerosis has a negative effect on treatment outcomes, functional status and decreased quality of life [32].

In conclusion it should be noted that the problem of cognitive disorders in the early period after surgery CEA is difficult issue to research. The variety of diagnostic tools provides problematic interpretation and make difficult to compare reported results with own data, but each of this study signals a potential disturbances and allow further evaluation.

\section{Conclusions}

Low or average level of cognitive performance is observed in most subjects, both before and after CEA but there are so many different factors that can affect the cognitive functions that it is difficult to determine the impact of only the procedure itself.

There are no significant differences in the functional fitness of subjects with internal carotid artery stenosis in the pre- and postoperative period. Almost all subjects were self-dependent in terms of basic and complex daily activities.

There is a relationship between the level of neurocognitive performance and level of complex daily activities in the pre- and postoperative period.

There is a need to perform further studies using specialized testing, but it is not easy to carry out them in the hospital. Assessment of neurocognitive disorders and the functional status of patients after CEA gives you the ability to monitor benefits accruing from the operation.

\section{Conflict of interest}

None.

\section{References:}

I. Bonati LH, Dobson J, Featherstone RL, et al. International Carotid Stenting Study investigators. Long-term outcomes after stenting versus endarterectomy for treatment of symptomatic carotid stenosis: the International Carotid Stenting Study (ICSS) randomised trial. Lancet. 2015; 385(9967): 529-538, doi: 10.1016/50140-6736(14)61184-3, indexed in Pubmed: 25453443.

2. Barnett HJM, Taylor DW, Haynes RB, et al. North American Symptomatic Carotid Endarterectomy Trial Collaborators. Beneficial effect of carotid endarterectomy in symptomatic patients with high-grade carotid stenosis. N Engl J Med. 1991; 325(7): 445-453, doi: 10.1056/NEJMI9910815325070I, indexed in Pubmed: 1852179.

3. Randomised trial of endarterectomy for recently symptomatic carotid stenosis: final results of the MRC European Carotid Surgery Trial (ECST). The Lancet. 1998; 35 I (91 13): 1379-1387, doi: 10.1016/s0 I40-6736(97)09292-I.

4. Endarterectomy for asymptomatic carotid artery stenosis. Executive Committee for the Asymptomatic Carotid Atherosclerosis Study. JAMA. 1995; 273(18): |42|-|428, indexed in Pubmed: 7723155. 
5. Halliday A, Mansfield A, Marro J, et al. MRC Asymptomatic Carotid Surgery Trial (ACST) Collaborative Group. Prevention of disabling and fatal strokes by successful carotid endarterectomy in patients without recent neurological symptoms: randomised controlled trial. Lancet. 2004; 363(9420): 149I-1502, doi: $10.1016 / 50140-6736(04) 16146-1$, indexed in Pubmed: I5I35594.

6. Mendonça CT, Fortunato JA, Carvalho CA, et al. Carotid endarterectomy in awake patients: safety, tolerability and results. Rev Bras Cir Cardiovasc. 2014; 29(4): 574-580, doi: 10.5935/I678974I.20140053, indexed in Pubmed: 257| 4212.

7. Takahashi Y, Ogasawara K, Matsumoto Y, et al. Changes in cognitive function after carotid endarterectomy in older patients: comparison with younger patients. Neurol Med Chir (Tokyo). 2013; 53(6): 353-359, indexed in Pubmed: 23803612.

8. Naylor AR, Ricco JB, Borst GJde, et al. Editor's Choice - Management of Atherosclerotic Carotid and Vertebral Artery Disease: 2017 Clinical Practice Guidelines of the European Society for Vascular Surgery (ESVS). European Journal of Vascular and Endovascular Surgery. 2018; 55(I): 3-8I, doi: 10.1016/j. ejvs.2017.06.02I.

9. Yoshida K, Ogasawara K, Kobayashi M, et al. Improvement and impairment in cognitive function after carotid endarterectomy: comparison of objective and subjective assessments. Neurol Med Chir (Tokyo). 2012; 52(3): 154-160, indexed in Pubmed: 22450480.

10. Feliziani FT, Polidori MC, De Rango P, et al. Cognitive performance in elderly patients undergoing carotid endarterectomy or carotid artery stenting: a twelve-month follow-up study. Cerebrovasc Dis. 2010; 30(3): 244-25I, doi: 10.1159/000319066, indexed in Pubmed: 20664257.

II. Altinbas A, Zandvoort Mv, Berg Ev, et al. Cognition after carotid endarterectomy or stenting: A randomized comparison. Neurology. 201 I; 77(1I): 1084-1090, doi: 10.1212/wnl. 0b013e31822e55b9.

12. Davis JC, Hsiung GY, Bryan S, et al. Agreement between patient and proxy assessments of quality of life among older adults with vascular cognitive impairment using the EQ-5D-3L and ICECAP-O. PLoS One. 2016; II(4): e0153878, doi: 10.137I/ journal.pone.0153878, indexed in Pubmed: 27101402.

13. Wilson DA, Mocco J, D'Ambrosio AL, et al. Post-carotid endarterectomy neurocognitive decline is associated with cerebral blood flow asymmetry on post-operative magnetic resonance perfusion brain scans. Neurol Res. 2008; 30(3): 302-306, doi: 10.1 179/016164107X230540, indexed in Pubmed: 17803842.

14. Heyer EJ, Sharma R, Rampersad A, et al. A controlled prospective study of neuropsychological dysfunction following carotid endarterectomy. Arch Neurol. 2002; 59(2): 217-222, indexed in Pubmed: I 1843692.

15. Mracek J, Holeckova I, Chytra I, et al. The impact of general versus local anesthesia on early subclinical cognitive function following carotid endarterectomy evaluated using $\mathrm{P} 3$ event-related potentials. Acta Neurochir (Wien). 2012; 154(3): 433-438, doi: 10.1007/s0070 I-0I I-1270-4, indexed in Pubmed: 22245975.

16. Takaiwa A, Kuwayama N, Akioka N, et al. Effect of carotid endarterectomy on cognitive function in patients with asymptomatic carotid artery stenosis. Acta Neurochir (Wien). 2013; 155(4): 627-633, doi: 10.1007/s0070I-013-1625-0, indexed in Pubmed: 23361637.
17. Kougias P, Collins R, Pastorek N, et al. Comparison of domain-specific cognitive function after carotid endarterectomy and stenting. J Vasc Surg. 2015; 62(2): 355-361, doi: 10.1016/j. jvs.2015.02.057, indexed in Pubmed: 262 I I 378.

18. Germano da Paz O, Guillaumon AT, Lopes TM, et al. Carotid stenting versus endarterectomy cognitive outcomes. Ann Vasc Surg. 2014; 28(4): 893-900, doi: 10.1016/j.avsg.2013.10.010, indexed in Pubmed: 2436/382.

19. Soinne L, Helenius J, Tatlisumak T, et al. Cerebral hemodynamics in asymptomatic and symptomatic patients with high-grade carotid stenosis undergoing carotid endarterectomy. Stroke. 2003; 34(7): 1655-|66|, doi: 10.1 |61/0 I.STR.0000075605.36068.D9, indexed in Pubmed: 12805504.

20. Capoccia L, Speziale F, Gazzetti M, et al. Comparative study on carotid revascularization (endarterectomy vs stenting) using markers of cellular brain injury, neuropsychometric tests, and diffusion-weighted magnetic resonance imaging. J Vasc Surg. 2010; 5I(3): 584-9I, 59I.el, doi: 10.1016/j.jvs.2009.10.079, indexed in Pubmed: 200456I4.

21. Korczyn AD, Vakhapova $V$. The prevention of the dementia epidemic. J Neurol Sci. 2007; 257(I-2): 2-4, doi: 10.1016/j. jns.2007.01.08I, indexed in Pubmed: 17490685.

22. Nicolaides AN, Kakkos SK, Kyriacou E, et al. Asymptomatic Carotid Stenosis and Risk of Stroke (ACSRS) Study Group. Asymptomatic internal carotid artery stenosis and cerebrovascular risk stratification. J Vasc Surg. 2010; 52(6): |486-1496.el, doi: 10.1016/j.jvs.2010.07.021, indexed in Pubmed: 21146746.

23. Popovic IM, Lovrencic-Huzjan A, Simundic AM, et al. Cognitive performance in asymptomatic patients with advanced carotid disease. Cogn Behav Neurol. 20II; 24(3): I45-I5I, doi: 10.1097/WNN.0b013e3182313020, indexed in Pubmed: 21945986.

24. Rexroth DF, Tennstedt SL, Jones RN, et al. Relationship of demographic and health factors to cognition in older adults in the ACTIVE study. J Aging Health. 2013; 25(8 Suppl): I28S-46S, doi: 10.1 177/08982643 |3498415, indexed in Pubmed: 24385633.

25. Stein J, Luppa M, Maier W, et al. AgeCoDe Study Group. Assessing cognitive changes in the elderly: reliable change indices for the Mini-Mental State Examination. Acta Psychiatr Scand. 2012; 126(3): 208-2|8, doi: 10.1 I I I/j.1600-0447.2012.01850.x, indexed in Pubmed: 22375927.

26. Barker-Collo S, Feigin VL, Parag V, et al. Auckland Stroke Outcomes Study. Part 2: Cognition and functional outcomes 5 years poststroke. Neurology. 2010; 75(18): 1608-1616, doi: 10.1212/ WNL.0b0 3e3।8Ifb44c8, indexed in Pubmed: 21041784.

27. McGuire LC, Ford ES, Ajani UA. Cognitive functioning as a predictor of functional disability in later life. Am J Geriatr Psychiatry. 2006; I4(I): 36-42, doi: 10.1097/01.JGP.0000192502.10692.d6, indexed in Pubmed: 16407580.

28. Opara J, Dmytryk J, Chromy M, et al. „Repty” stroke scale . "Repty" Scale for the evaluation of the degree of injury after cerebral stroke. Part I. Neurol Neurochir Pol. 1998; 32(4): 793-802, indexed in Pubmed: 9864708.

29. Landgraff NC, Whitney SL, Rubinstein EN, et al. Cognitive and physical performance in patients with asymptomatic carotid artery disease. J Neurol. 2010; 257(6): 982-991, doi: 10.1007/ s004I5-009-5449-z, indexed in Pubmed: 20099067.

30. Arts MHL, Collard RM, Comijs HC, et al. Physical frailty and cognitive functioning in depressed older adults: find- 
ings from the NESDO study. J Am Med Dir Assoc. 2016; 17(1): 36-43, doi: 10.1016/j.jamda.2015.07.016, indexed in Pubmed: 2634I037.

3I. O'Donnell MJ, Chin SL, Rangarajan S, et al. INTERSTROKE investigators, INTERSTROKE investigators. Risk factors for ischaemic and intracerebral haemorrhagic stroke in 22 countries (the INTERSTROKE study): a case-control study. Lancet. 2010;
376(9735): I |2-123, doi: I0.I0|6/S0|40-6736(I0)60834-3, indexed in Pubmed: 20561675.

32. Carta MG, Lecca ME, Saba L, et al. Patients with carotid atherosclerosis who underwent or did not undergo carotid endarterectomy: outcome on mood, cognition and quality of life. BMC Psychiatry. 2015; 15: 277, doi: 10.1 186/s | 2888-015-0663-y, indexed in Pubmed: 26563766. 